\title{
PENGARUH PENAMBAHAN LIMBAH B3 PADA KUAT BETON MUTU K-175
}

\author{
Bobby Damara ${ }^{1}$, Zulkifli Lubis ${ }^{2}$ \\ 'Program Studi Teknik Sipil Fakultas Teknik Sipil Universitas Islam Lamongan \\ ${ }^{2}$ Dosen Fakultas Teknik Universitas Islam Lamongan, \\ email: cheppy.lubis@gmail.com
}

\begin{abstract}
Innovations of concrete growing quite rapidly now from reuse and reduce. materials unused or addition of additives in order to increase the quality of concrete include the addition of waste carbide (B3) is an effort to increase the element calcium is required in the reaction pozzolanic when mixed with $\mathrm{SiO} 2$ in the fly ash, Pozzolanic reaction is a reaction between calcium, silica or aluminates with water to form a strong and rigid mass similar to the cement hydration process. The mixing process carbide waste as a concrete material is done by laboratory testing in accordance with data from literature Indonesian Standard SK SNI and foreign standards are ASTM with variation of composition dregs carbide 5\% as a substitute for cement material with a target quality of concrete $K-175$. From this result the composition of dregs addition of a mixture of dregs carbide 5\% with an average compressive strength of $249,69 \mathrm{~kg} / \mathrm{cm} 2$. That value greater than $1,77 \%$ of the normal concrete $245,36 \mathrm{~kg} / \mathrm{cm} 2$.
\end{abstract}

Keywords : carbide waste (B3), concrete, compressive strength.

\section{PENDAHULUAN}

Kualitas mutu beton sering dikaitkan dengan kuat tekan beton, semakin tinggi kuat tekan maka semakin baik kualitas dari beton. Kualitas beton tergantung dari bahan baku yang dipakai sebagai perekat atau sebagai agregat. Perekat yang biasa dipakai adalah semen dan agregat yang digunakan pasir.

Inovasi beton sekarang mengalami perkembangan yang cukup pesat dari reuse dan reduce bahan material tak terpakai atau penambahan zat aditif dengan tujuan agar bertambahnya kualitas mutu beton itu sendiri dan bertambahnya nilai ekonomis dari bahan yang tak terpakai seperti abu sekam, pecahan keramik dan berbagai ampas atau bahkan limbah dari adukan beton itu sendiri.

Peraturan Pemerintah Nomor 101 tahun 2014 tentang Pengelolaan Limbah Bahan Berbahaya dan Beracun mendefinisikan Bahan Berbahaya dan Beracun (B3) sebagai zat, energi, dan/atau komponen lain yang karena sifat, konsentrasi, dan/atau jumlahnya, baik secara langsung maupun tidak langsung, dapat mencemarkan dan/atau merusak lingkungan hidup, dan/atau membahayakan lingkungan hidup, kesehatan, serta kelangsungan hidup manusia dan makhluk hidup lain.

Limbah B3 yang digunakan dalam penelitian adalah limbah karbit. Limbah karbit merupakan sisa dari reaksi karbit terhadap air yang menghasilkan gas acyetilene. Limbah karbit itu sendiri sangat mudah dijumpai pada bengkel-bengkel las acyetilene di daerah Lamongan yang pada umumnya tidak dilakukan pengolahan terhadap limbah karbit tersebut karena dianggap tidak bernilai ekonomis dan mengandung zat berbahaya. Seiring berkembangnya teknologi dan inovasi beton solusi pengurangan limbah karbit yang yang menumpuk di daerah Lamongan adalah dengan melakukan pemakaian kembali (Reuse) agar dapat dimanfaatkan sebagai material bahan konstruksi bangunan lain yang ramah terhadap lingkungan. Tujuannya adalah untuk dan mengurangi limbah (B3) yang dapat mencemari lingkungan sekitar dan mewujudkan pembangunan yang berkesinambungan (sustainable construction) yang dilakukan oleh masyarakat. 
Pada penelitian terdahulu telah terbukti limbah ampas karbit mampu menaikan kualitas mutu beton dengan komposisi terbaik pada pembuatan beton campuran limbah karbit ini adalah pada komposisi limbah karbit $10 \%$ dengan kuat tekan sebesar $18,59 \mathrm{MPa}$ dengan kenaikan sebesar 13,14\% dibanding beton normal.

Tujuan penelitian ini adalah untuk mengetahui pengaruh kuat tekan beton dengan penambahan limbah ampas dari sisa karbit las acyetilene dengan komposisi penambahan $5 \%$.

\section{METODE PENELITIAN}

Metode penelitian ini dilakukan dengan cara pengujian di laboratorium sesuai dengan data-data dari studi pustaka Standar Indonesia SK SNI maupun standar asing yaitu ASTM.

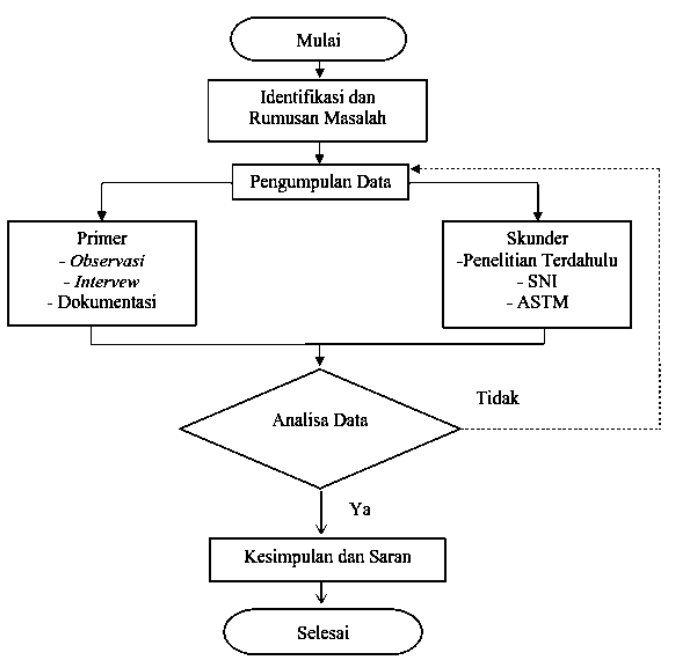

Gambar 1 Flow Chart Penelitian

Sampel yang dibuat adalah beton keras dengan perbandingan komposisi campuran yang didapat sebelumnya dari hasil mix design beton normal mutu sedang yaitu dengan besar kuat tekan K-175 yang kemudian ditambah dengan bahan ampas karbit (Limbah B3) sebagai bahan campuran beton, adalah sebagai berikut :

Tabel 1 Prosentase komposisi bahan pada masing-masing varisasi campuran beton

\begin{tabular}{ccc}
\hline Kode & Semen & Ampas karbit \\
\hline Normal & $100 \%$ & $0 \%$ \\
B 5\% & $95 \%$ & $5 \%$ \\
\hline
\end{tabular}

Sumber : Hasil perhitungan
Langkah langkah yang akan dilakukan dalam penelitian pemanfaatan ampas karbit (Limbah B3) sebagai bahan campuran beton adalah sebagai berikut :

1. Melakukan pengujian analisa saringan distribusi ukuran butir / gradasi ampas karbit.

2. Melakukan pengujian waktu mengikat dan mengeras semen ditambah ampas karbit.

3. Mempersiapkan alat-alat yang digunakan dalam penelitian. Persiapan alat meliputi satu set alat vikat, cetakan silinder $15 \times 30 \mathrm{~cm} 12$ buah, mesin uji kuat tekan.

4. Melakukan pengujian bahan susun beton meliputi :

a. Pengujian bahan semen :

- Pengujian konsistensi normal semen portland

- Pengujian waktu mengikat dan mengeras semen

- Pengujian berat jenis semen

b. Pengujian agregat Halus :

- Pengujian analisa saringan distribusi ukuran butir / gradasi pasir

- Pengujian kadar air agregat halus

- Pengujian berat jenis pasir pada kondisi SSD

- Pengujian kadar air resapan pasir

- Pengujian berat volume pasir baik dalam keadaan lepas maupun terikat.

c. Pengujian agregat Kasar :

- Pengujian analisa saringan distribusi ukuran butir / gradasi batu pecah

- Pengujian kelembapan batu pecah

- Pengujian berat jenis batu pecah pada kondisi SSD

- Pengujian kadar air resapan kerikil

- Pengujian berat volume batu pecah baik dalam keadaan lepas maupun terikat.

d. Pengujian beton segar :

- Pengujian slump test

- Pengujian berat isi beton

e. Pengujian beton keras :

- Pengujian kuat tekan

- Pengujian berat isi beton keras 


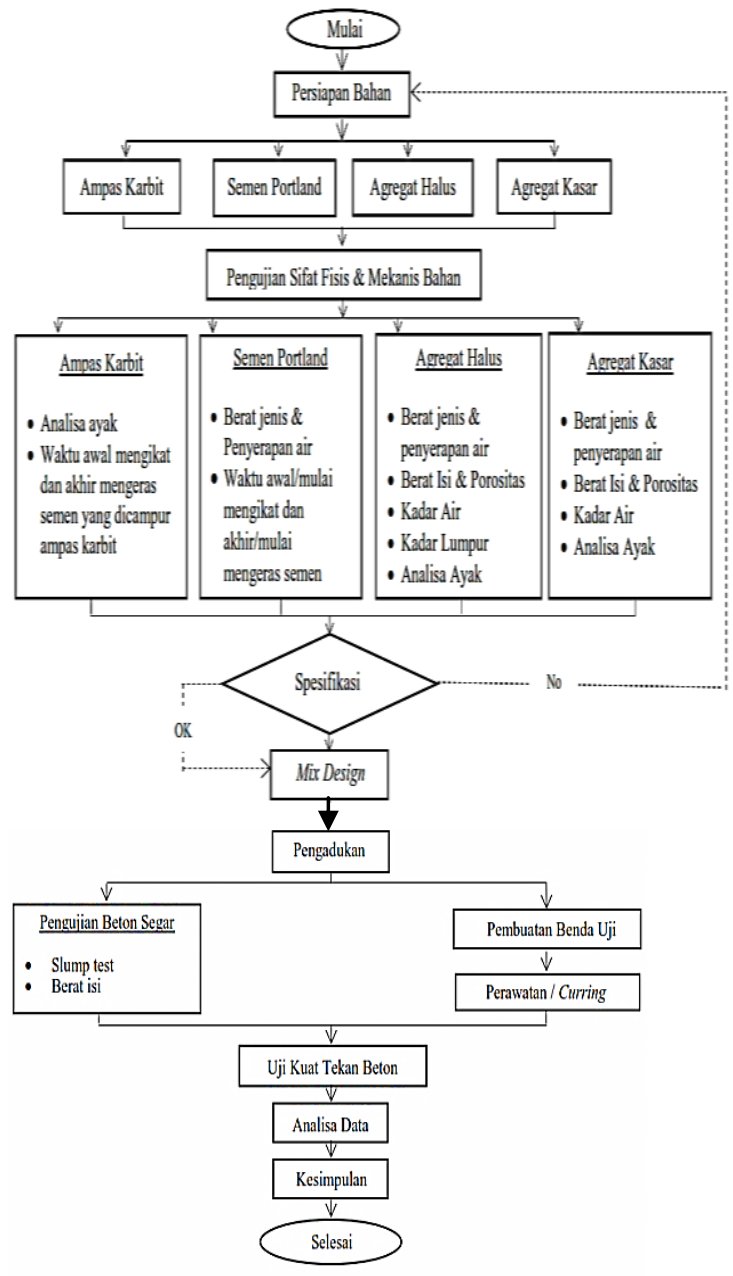

Gambar 2 Flow Chart Pembuatan Beton

\section{HASIL DAN PEMBAHASAN}

Perencanaan campuran beton mengacu pada SNI 03-2834-2000 dengan menggunakan campuran ampas karbit sebagai pengganti semen, dimana dalam pengujian beton merujuk pada beton mutu rendah dengan kuat tekan K-175.

\section{Pengujian Bahan Semen}

Semen portland yang digunakan dalam penelitian ini merupakan semen gresik.

Tabel 2 Konsistensi Normal Semen Portland

\begin{tabular}{cccc}
\hline Percobaan Nomor & 1 & 2 & 3 \\
\hline Semen ( W1 ) gr & 250 & 250 & 250 \\
Air (W2 ) cc & 70 & 80 & 90 \\
Penetrasi & 10 & 16 & 27 \\
Konsistensi ( (W2 / W1) * & 28 & 32 & 36 \\
$100 \%)$ & $\%$ & $\%$ & $\%$ \\
\hline
\end{tabular}

Sumber : Hasil penelitian

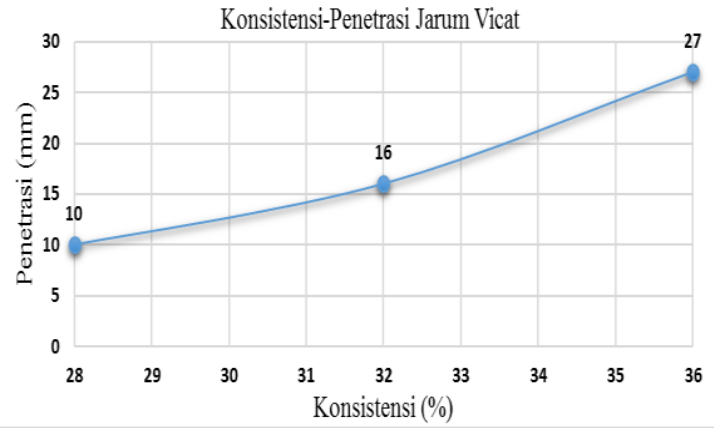

Gambar 3 Grafik Konsistensi-Penetrasi Semen Portland

Hasil pengujian konsistensi normal semen portland mendapat kebasahan pasta rata-rata sebesar $28 \%$.

Tabel 3 Waktu Pengikatan Awal (Initial) dan Pengerasan Semen (Final)

\begin{tabular}{cc}
\hline $\begin{array}{c}\text { Waktu Penurunan } \\
\text { ( Menit })\end{array}$ & $\begin{array}{c}\text { Penurunan } \\
(\mathrm{mm})\end{array}$ \\
\hline 45 & $41 \mathrm{~mm}$ \\
60 & $36 \mathrm{~mm}$ \\
75 & $33 \mathrm{~mm}$ \\
90 & $30 \mathrm{~mm}$ \\
105 & $22 \mathrm{~mm}$ \\
120 & $19 \mathrm{~mm}$ \\
135 & $14 \mathrm{~mm}$ \\
150 & $10 \mathrm{~mm}$ \\
165 & $7 \mathrm{~mm}$ \\
180 & $5 \mathrm{~mm}$ \\
195 & $0 \mathrm{~mm}$ \\
\hline
\end{tabular}

Sumber : Hasil penelitian

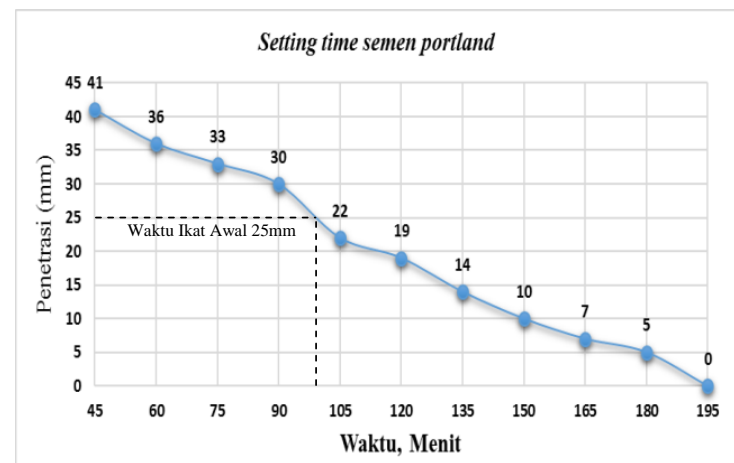

Gambar 4 Grafik Setting Time Pengikatan Awal (Initial) dan Pengerasan (Final)

Hasil pengujian pengikatan dan mengeras semen portland sesuai dengan syarat SNI 036827-2002 yaitu antara 45 menit (intial) dan tidak lebih dari 375 menit (final). 
Tabel 4 Pengujian Berat Jenis Semen

\begin{tabular}{ccc}
\hline Percobaan Nomor & I & II \\
\hline $\begin{array}{c}\text { Semen ( w1 ) - ( gr ) } \\
\text { semen+minyak+labu takar } \\
\text { (w2 ) - ( gr ) }\end{array}$ & 250 & 250 \\
labu takar+minyak (w3)-(gr) & 328,5 & 328,5 \\
Bj = 0.8 w1 / ( w1 + w3 - w2 ) & 2,367 & 2,291 \\
\hline Sumber : Hasil penelitian \\
Berat jenis rata-rata $=\frac{\text { Percobaan I+Percobaan II }}{2}$ \\
$=\frac{2,367+2,291}{2}=2,329$ gr
\end{tabular}

\section{Pengujian Agregat Halus}

Tabel 5 Test Kondisi Analisa Ayakan Pasir

\begin{tabular}{cccc}
\hline Saringan & \multicolumn{2}{c}{ Tertinggal pada } & \multirow{2}{*}{$\begin{array}{c}\text { Ayakan } \\
\text { Kumulatif } \\
\text { Tertahan }\end{array}$} \\
\cline { 1 - 3 } Mm & Gram & $\%$ & \\
\hline 4.80 & 7 & 0,702 & 0,702 \\
2.40 & 20 & 2,006 & 2,708 \\
1.20 & 161 & 16,148 & 18,857 \\
0.60 & 308 & 30,893 & 49,749 \\
0.30 & 497 & 49,147 & 98,897 \\
0.15 & 7 & 0,702 & 99,599 \\
0 & 4 & 0,401 & 100 \\
Jumlah & 997 & 100 & 370,5 \\
\hline \multicolumn{2}{l}{ Sumber : Hasil penelitian } & &
\end{tabular}

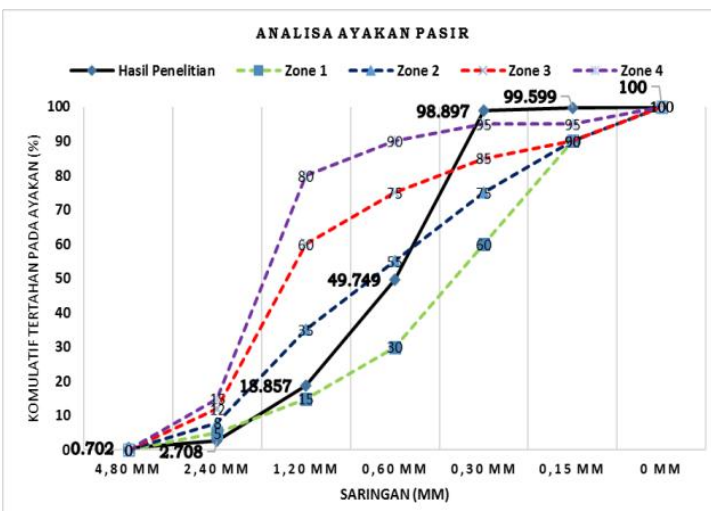

Gambar 5 Grafik Analisa Ayakan Pasir

$$
\begin{aligned}
\text { Fm } & =\frac{\sum \% \text { tertahan komulaif dari saringan no. } 200}{100} \\
& =\frac{99,599+98,897+49,749+18,857+2,708+0,702}{100} \\
& =\frac{270,5}{100}=2,705 \mathrm{gr}
\end{aligned}
$$

Dari hasil penelitian agregat halus berada pada zone 1
Tabel 6 Pengujian Kelembaban Agregat Halus

\begin{tabular}{lcc}
\hline Percobaan Nomor & I & II \\
\hline pasir asli (w1) - (gr) & 500 & 500 \\
pasir oven (w2) - (gr) & 469 & 478 \\
$\begin{array}{l}\text { Kelembaban pasir :(w1- } \\
\text { w2)/w2 x 100\% }\end{array}$ & $6,61 \%$ & $4,60 \%$ \\
\hline
\end{tabular}

Sumber : Hasil penelitian

Rata-rata kelembaban $=\frac{6.61+4.60}{2}=5,605 \%$

Tabel 7 Pengujian Berat Jenis Agregat Halus SSD

\begin{tabular}{lcc}
\hline Percobaan Nomor & I & II \\
\hline labu + pasir + air ( w1 )-(gr) & 822 & 827,6 \\
pasir SSD ( w2)-(gr) & 250 & 250 \\
labu + air ( w3 )-(gr) & 670 & 670,4 \\
BJ pasir ((w2/((w2+w3)-w1) & 2,55 & 2,69 \\
\hline Sumber : Hasil penelitian & & \\
BJ rata-rata $=\frac{2,55+2,69}{2}=2,62 \mathrm{gr} / \mathrm{dm}^{3}$
\end{tabular}

Tabel 8 Pengujian Air Resapan Agregat Halus

\begin{tabular}{lcc}
\hline Percobaan Nomor & I & II \\
\hline pasir SSD - (gr) & 500 & 500 \\
pasir oven (w1) - (gr) & 475 & 486 \\
Kadar air resapan : ((500 & $2,80 \%$ & $2,76 \%$ \\
- w1 )/w1) x 100\% & & \\
\hline Sumber : Hasil penelitian & &
\end{tabular}

Rata-rata kadar air resapan $=\frac{2,80+2,76}{2}=$ $2,78 \%$

\begin{tabular}{|c|c|c|c|}
\hline \multirow{2}{*}{$\frac{\text { Saringan }}{\mathrm{mm}}$} & \multicolumn{2}{|c|}{$\begin{array}{l}\text { Tertinggal pada } \\
\text { Ayakan }\end{array}$} & \multirow{2}{*}{$\begin{array}{c}\% \\
\text { Komulatif } \\
\text { Tertinggal }\end{array}$} \\
\hline & Gram & $\%$ & \\
\hline 25.4 & 119 & 1,190 & 1,190 \\
\hline 19.1 & 1727 & 17,223 & 18,414 \\
\hline 12.5 & 4006 & 40,068 & 58,482 \\
\hline 9.5 & 2401 & 24,015 & 82,496 \\
\hline
\end{tabular}

\section{Pengujian Agregat Kasar}

Tabel 9 Hasil Analisa Ayakan Batu Pecah 


\begin{tabular}{|c|c|c|c|}
\hline \multirow{2}{*}{$\begin{array}{c}\text { Saringan } \\
\mathrm{mm}\end{array}$} & \multicolumn{2}{|c|}{$\begin{array}{c}\text { Tertinggal pada } \\
\text { Ayakan }\end{array}$} & \multirow{2}{*}{$\begin{array}{c}\% \\
\text { Komulatif } \\
\text { Tertinggal }\end{array}$} \\
\hline & Gram & $\%$ & \\
\hline 4.76 & 780 & 7,802 & 90,298 \\
\hline 2.38 & 460 & 4,601 & 94,899 \\
\hline \multirow[t]{2}{*}{0} & 510 & 5,101 & 100 \\
\hline & 9998 & 100 & 445,78 \\
\hline
\end{tabular}

Jumlah Fm Batu Pecah $=445,78 / 100$

$$
=4,458
$$

Sumber : Hasil penelitian

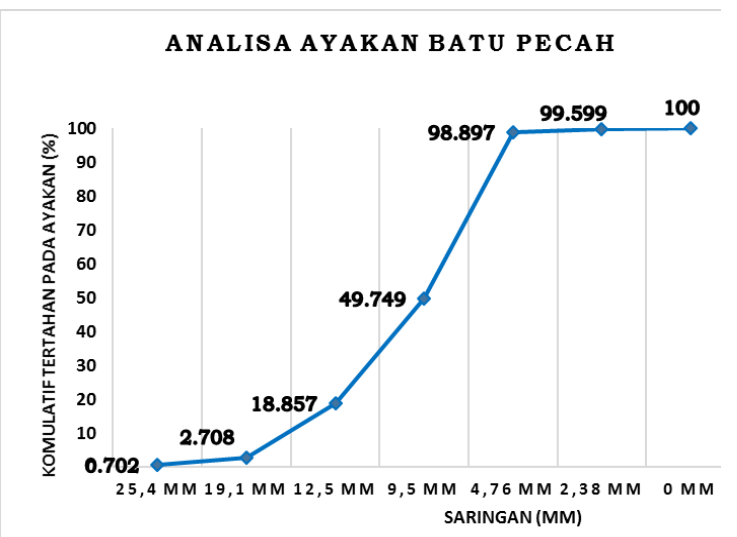

Gambar 5 Grafik Analisa Ayakan Batu Pecah

$\mathrm{Fm}=\frac{\Sigma \% \text { tertahan } \text { komulaif dari saringan no.200 }}{100}$

$=\frac{1,190+18,414+58,482+82,496+90,298+94,899+100}{100}$

$=\frac{445,78}{100}=4,458 \mathrm{gr}$

Dari nilai FM yang didapat gradasi agregat kasar cenderung pipih / tidak kasar

Tabel 10 Hasil Pengujian Kelembaban Kerikil

\begin{tabular}{ccc}
\hline Percobaan Nomor & I & II \\
\hline kerikil asli ( w1 ) - (gr) & 1000 & 1000 \\
kerikil oven ( w2 ) - (gr) & 988 & 987 \\
$\begin{array}{c}\text { Kelembaban kerikil : (w1 } \\
\text { - w2)/w2 x 100\% }\end{array}$ & $1,21 \%$ & $1.32 \%$ \\
\hline Sumber : Hasil penelitian & &
\end{tabular}

Rata-rata $=\frac{1,21+1,32}{2}=1,265 \%$

Tabel 11 Hasil Pengujian Berat Jenis Kerikil

\begin{tabular}{lcc}
\hline Percobaan Nomor & I & II \\
\hline Berat di udara (w1) - (gr) & 3000 & 3000 \\
Berat di air (w2) - (gr) & 1729 & 1740 \\
BJ = w1/(w1 - w2) & 2.36 & 2.38 \\
\hline
\end{tabular}

Sumber : Hasil penelitian

Rata-rata $=\frac{2,36+2,38}{2}=2,37 \mathrm{gr} / \mathrm{dm}^{3}$

Tabel 12 Hasil Pengujian Kadar Air Resapan Batu Pecah

\begin{tabular}{lcc}
\hline Percobaan Nomor & I & II \\
\hline kerikil asli ( w1 ) - (gr) & 1000 & 1000 \\
kerikil oven ( w2 ) - (gr) & 983 & 980 \\
$\begin{array}{l}\text { Kadar air resapan kerikil : } \\
\text { (w1 - w2)/w2 x 100\% }\end{array}$ & $1.73 \%$ & $2.04 \%$ \\
\hline Sumber : Hasil penelitian & &
\end{tabular}

$\mathrm{BJ}$ rata-rata $=\frac{1,73+2,04}{2}=1,88 \%$

\section{Pengujian Bahan Tambah (Ampas Karbit)}

Penambahan limbah karbit sebagai bahan campuran beton merupakan upaya untuk meningkatkan unsur kalsium. Limbah karbit mengandung sekitar $60 \%$ unsur kalsium dan limbah karbit termasuk dalam kategori limbah B3 (Bahan Berbahaya dan Beracun). Komposisi kimia limbah karbit antara lain yaitu :

Tabel 13 Kandungan Limbah Karbit

\begin{tabular}{cc}
\hline Komposisi kimia & Kandungan \% \\
\hline $\mathrm{SiO}_{2}$ & 4,3 \\
$\mathrm{Fe}_{2} \mathrm{O}_{3}$ & 0,9 \\
$\mathrm{Al}_{2} \mathrm{O}_{3}$ & 0,4 \\
$\mathrm{CaO}$ & 56,5 \\
$\mathrm{MgO}$ & 1,7 \\
$\mathrm{SO}_{3}$ & 0,06 \\
Lol & 36,1 \\
\hline Sumber : PT. VARIA USAHA BETON \\
(dalam jurnal Dewi, dkk, 2016)
\end{tabular}




\begin{tabular}{|c|c|c|c|c|}
\hline $\begin{array}{l}\text { Pengu. } \\
\text { Ampas }\end{array}$ & $\begin{array}{l}\text { an } \\
\text { Karb }\end{array}$ & nalisa & Saringan & Gradasi \\
\hline Tabel & $4 \mathrm{Tes}$ & ondisi & akan ampa & karbit \\
\hline Sarir & & Terti & $\begin{array}{l}\text { gal pada } \\
\text { akan }\end{array}$ & $\begin{array}{c}\text { Kumulatif } \\
\text { Tertahan }\end{array}$ \\
\hline Nomor & $\mathrm{Mm}$ & Gram & $\%$ & \\
\hline 4 & 4,76 & 0 & 0 & 0 \\
\hline 8 & 2,38 & 0 & 0 & 0 \\
\hline 30 & 0,59 & 0 & 0 & 0 \\
\hline 50 & 0,3 & 443 & 44 & 44 \\
\hline 100 & 0,15 & 316 & 32 & 76 \\
\hline 200 & 0,08 & 174 & 17 & 94 \\
\hline Pan & 0 & 64 & 6 & 100 \\
\hline Jum & & 997 & 100 & 370,5 \\
\hline
\end{tabular}

Sumber : Hasil Penelitian

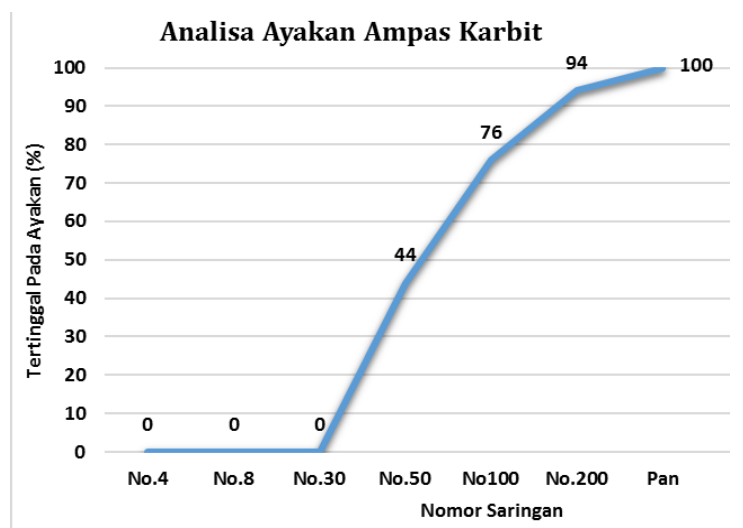

Gambar 6 Grafik Test Analisa Kondisi Ayakan Ampas Karbit

Tujuan pengujian analisa saringan distribusi ukuran butir ampas karbit adalah untuk menentukan gradasi atau pembagian ukuran butir ampas karbit dari suatu sample dengan menggunakan saringan 50, 100 dan 200 dan hanya ampas karbit yang lolos saringan $200(0,0745 \mathrm{~mm})$ tertinggal pada pan saringan yang digunakan sebagai bahan campuran beton.

\section{Pengujian Waktu Mengikat Dan Mengeras Semen Ditambah Ampas Karbit}

Tabel 15 Pengikatan Awal dan Pengerasan

\begin{tabular}{ccc}
\hline $\begin{array}{c}\text { Waktu } \\
\text { Komulatif } \\
\text { (Menit) }\end{array}$ & \multicolumn{2}{c}{ Penurunan $(\mathrm{mm})$} \\
\cline { 2 - 3 } & Beton Normal & B 5\% \\
\hline 45 & 41 & 40 \\
60 & 36 & 36 \\
75 & 33 & 34 \\
90 & 30 & 28 \\
\hline
\end{tabular}

\begin{tabular}{ccc}
\hline \multirow{2}{*}{$\begin{array}{c}\text { Waktu } \\
\text { Komulatif } \\
\text { (Menit) }\end{array}$} & \multicolumn{2}{c}{ Penurunan ( mm ) } \\
\cline { 2 - 3 } & Beton Normal & B 5\% \\
105 & 22 & 23 \\
120 & 19 & 19 \\
135 & 14 & 13 \\
150 & 10 & 9 \\
165 & 7 & 6 \\
180 & 5 & 3 \\
195 & 0 & 1 \\
210 & - & 0 \\
225 & - & - \\
\hline
\end{tabular}

Sumber : Hasil Penelitian

Pengujian waktu Pengikatan Awal (Initial) dan Pengerasan Semen ditambah Ampas Karbit (Final) dibutuhkan waktu 90105 menit mencapai pengikatan awal dan waktu pengerasan mencapai 210 menit untuk campuran ampas karbit 5\%. Percobaan waktu pengikatan dan mengeras semen yang tercampur ampas karbit diatas sesuai dengan syarat SNI 03-6827-2002 yaitu antara 45-200 menit (initial) dan tidak lebih dari 375 menit (final). Waktu ikat awal tercapai apabila masuknya jarum vicat ke dalam sampel dalam waktu 30 detik sedalam $25 \mathrm{~mm}$.

\section{Kuat Tekan Beton}

Pengujian kuat tekan beton ini mengacu pada SNI 03-1947-1990 pengujian kuat tekan ini dimaksudkan sebagai pegangan dalam pengujian untuk menentukan kuat tekan (compressive strength) beton dengan benda uji berbentuk silinder yang dibuat dan dimatangkan (curring) di laboratorium. Tujuan pengujian kuat tekan beton adalah untuk mengetahui komposisi bahan susun beton terutama penambahan ampas karbit memenuhi mutu yang direncanakan yaitu beton mutu K-175. Hasil kuat tekan beton dapat dilihat pada Tabel 16 dan Gambar 7.

Tabel 16 Hasil Kuat Tekan Beton

\begin{tabular}{ccccc}
\hline $\begin{array}{c}\text { Kode } \\
\text { Beton }\end{array}$ & Umur & $\begin{array}{c}\text { Kuat Tekan } \\
\text { Rata-Rata } \\
(\mathrm{kg} / \mathrm{cm} 2)\end{array}$ & FK & $\begin{array}{c}\text { Teg. } \\
\text { Hancur } \\
28 \text { hari } \\
(\mathrm{kg} / \mathrm{cm} 2)\end{array}$ \\
\hline Normal & 7 Hari & 159,47 & 0.65 & 245,34 \\
B5\% & 7 Hari & 162,30 & 0.65 & 249,69 \\
\hline \multicolumn{5}{l}{ Sumber : Hasil penelitian }
\end{tabular}




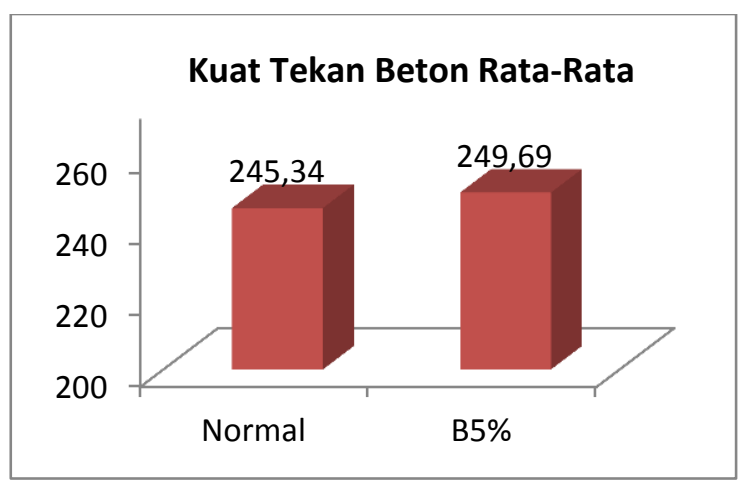

Gambar 7 Grafik rata-rata kuat tekan beton

Dengan penambahan limbah karbit 5\% memiliki kuat tekan beton lebih besar dari beton normal. Penambahan kuat tekan beton sekitar $1,77 \%$ dari beton normal.

\section{KESIMPULAN}

Kesimpulan dari penelitan ini adalah pada pembuatan beton campuran ampas karbit ini adalah pada komposisi ampas karbit 5\% kuat tekan rata-rata sebesar $249,69 \mathrm{~kg} / \mathrm{cm} 2$ dengan kenaikan sebesar $1,77 \%$ dibanding beton normal yang mencapai tegangan hancur ratarata 245,34 .

\section{SARAN}

Saran untuk penelitian lebih lanjut adalah :

1. Perlu dilakukan penelitian lebih lanjut terhadap penggunaan ampas karbit, agar didapat nilai persentase pemakaian yang maksimum terhadap sifat mekanis beton.

2. Lakukan penelitian dengan range ampas karbit $1 \%-5 \%$.

3. Perlu dilakukan analisa kesehatan terhadap pemakaian limbah karbit pada campuran beton.

\section{DAFTAR PUSTAKA}

ASTM C 33-03 Standard Specification for Concrete Aggregates

ASTM C-566- 97 (Reapproved 2004), Standard method for total moisture content of aggregate by drying

ASTM - C 188 - 95 (Reapproved 2003) Standard Test Method forDensity of Hydraulic Cement

ASTM C 127-88-93 Specific Gravity and Absorption of Coarse Aggregate

ASTM C-187-86 Standard Test Method for Normal Consistency of Hydraulic Cement
ASTM C 128-78 Specific Gravity and Absorption of Fine

Dewi, NR., dkk (2016). Studi Pemanfaatan Limbah B3 Karbit Dan Fly Ash Sebagai Bahan Campuran Beton Siap Pakai (Bsp). (online). Tersedia http://ejournal.undip.ac.id/indexphp/presi pitasi/article/download/11107/8731

Peraturan Pemerintah Republik Indonesia, 2014. Pengelolaan Limbah Bahan Berbahaya dan Beracun

Standar Nasional Indonesia 2002. SNI 036827-2002 Metode pengujian waktu ikat awal semen portland dengan menggunakan alat vicat

Standar Nasional Indonesia 2000. SNI 032834-2000 : Tata Cara Pembuatan Rencana Campuran Beton Normal

Standar Nasional Indonesia 1990. SNI 031970-1990 Metode Pengujian Berat Jenis dan Penyerapan Air Agregat Halus

Standar Nasional Indonesia 1990. SNI-031969-1990 Metode Pengujian Berat Jenis dan Penyerapan Air Agregat Kasar

Standar Nasional Indonesia 1989. SNI S - 04 - 1989 - F Metode Pengujian Analisis Saringan Agregat Halus 
Halaman ini sengaja dikosongkan 